Engineering \& Science

JANUARY-FEBRUARY 1978

\title{
Outline for \\ An Acceptable Nuclear Future
}

\author{
by ALVIN M. WEINBERG
}

N ances offered by its proponents, a substantial, and possibly growing fraction of the public is uneasy about the course we are following. To be sure, the nuclear moratorium bills in the United States have been defeated at the polls by a vote of 2 to 1 . Nuclcar proponents point to the two-thirds who favor nuclear development and consider this a mandate to go ahead. But I think it is fair to say that a primary energy system that is feared or rejected by 33 percent of the public is not going to survive.

Three possibilities emerge. First, that nuclear energy will gradually disappear and, except for the bomb, the world will revert to the situation that existed before December 2, 1942, when the first man-made chain reaction was established. One must remember that fission itself is rather a fluke. The conditions for establishing a self-sustaining chain reaction might not have been met had the number of neutrons per fission been less than 1 , or if man had evolved after all of the ${ }^{235} \mathrm{U}$ had disappeared. There was nothing pre-ordained about fission energy or the discovery of fission in 1938. Had this discovery been delayed by 50 years, we would somehow be doing without it.

The second possibility is that our fears about fission energy may simply subside. As man acquires more experience with reactors, and more particularly, as the public acquires familiarity with radiation, it is quite possible that the opposition to fission will wane. The analogy with the introduction of electricity is close. There are still some elderly people around who were once uncomfortable about electricity; yet these fears have largely disappeared as electricity has become part of everyday living.

An essential element is missing in this analogy: the bomb. Even though we resolve our concerns about personal safety, or even genetic hazard, the bomb and proliferation make nuclear energy special. It is on this account that I believe nuclear energy will never be accepted to the unquestioning degree that electricity has been accepted.

The third possibility is that we can devise fixestechnological and institutional-that will make nuclear. energy acceptable. Can we draft a peace treaty between those who oppose nuclear energy and those who support nuclear energy? Can we outline an acceptable nuclear future?

Acceptability and need are conjugates. What is acceptable, and how much risk we are willing to take, depends on how badly we need, or think we need, nuclear energy. This perception of need depends both upon our projections of energy demand and upon the energy situation at a given time. To be sure, the rate at which nuclear energy was introduced in the United States was determined pretty much by competitive market forces rather than by perception of energy demand. (And it is notable that in the Soviet Union nuclear power has been introduced at less than onefifth the rate it has been introduced here.) But once nuclear power has been introduced, once a $\$ 75$ billion industry is in being, the need for continuing the enterprise is overwhelming. It would be disastrous, at least in the short run, simply to shut down the nuclear enterprise, what with oil embargoes and other energy shortages.

What is at issue, then, is not so much what is to be done with the nuclear system already in place; it is what is to be done in the future. If this future is perceived to be a high-energy future, then the need for nuclear energy and the acceptable risk are correspondingly higher; if it is a low-energy future, the need, and therefore the acceptable risk, is lower.

SEMANTIC CONFUSIONS AND CONSENSUAL CIIMATES

Let us first dispose of a semantic confusion-the two meanings of the word "acceptable." As the nuclear 
enterprise now stands, it is acceptable neither to those who oppose nuclear energy nor to those who favor it. It is unacceptable to the former because they consider it somehow too dangerous. It is unacceptable to the nuclear industry because they are frustrated by administrative delay and uncertainty, by serious cost overruns, and by continual bickering.

But most of the frustration of the proponents simply reflects the basic unacceptability of nuclear energy to the opponents; many of these frustrations would disappear if nuclear energy were acceptable to the opponents. The regulatory process is lengthy and courtridden not because the regulators are poorly organized or doing a bad job, but rather because the underlying technology that is being regulated has not received an adequate consensus. In the absence of such consensus, the regulatory process has become subverted; it becomes an instrument for bringing to focus the profound differences in perception between pros and antis, and in the process it frustrates nuclear energy. Indeed, the process becomes a background for what has been described as a religious war. Thus, although some of the fixes that I propose will be aimed at getting nuclear energy off dead center, I consider these secondary. Unless we can arrive at a system that commands a consensus, any fixes that satisfy only the pros will be submerged in the overall opposition.

It can be argued that we set an impossible task. How do we know when an adequate consensus has been achieved? Who, after all, speaks on whose behalf? Which antis are to be placated, which pros are to negotiate? In a democratic representati'e society, are we not constrained to use the duly constituted instruments of authority - our elected representatives, our regulatory bodies, our judicial system? I doubt that anyone has a clear conception as to how to fully legitimize dissent when it is deep-rooted and widespread. Nevertheless, our system has been resilient enough to establish what I might call "consensual climates" even on issues that at one time were bitterly divisive. Civil rights was deeply divisive, yet it was finally largely resolved. We have achieved a consensual climate with respect to this issue. It is this consensual climate with respect to nuclear energy that we seek to establish without giving up nuclear energy.

\section{CRITERIA TO BE MET}

What really bothers opponents of nuclear energy? The opposition is concerned with issues at three differ- ent levels. First is growth. Those who are opposed to growth as a matter of principle are opposed to nuclear energy since nuclear energy, insofar as it is unlimited, gives the technological base for unlimited growth. Related to this concern is centralization and bureaucratization; growth can be managed only by centralization, and centralization is bad. Since nuclear energy is the epitome of centralized technology, it evokes fears among those who long for a decentralized and, one hopes, a more resilient society.

The second concern has to do with proliferation; indeed, this at the moment seems to be the main objection to nuclear energy. There are many who insist that no nuclear energy system can be devised to be proliferation-proof, and that this alone warrants a rejection of nuclear energy. Proliferation is of course not indissolubly connected with nuclear power. The best one can hope for is a way of delaying, not stopping, proliferation.

Finally, there are the concerns over the intrinsic safety of nuclear energy - waste disposal, reactor accidents, routine emissions, possible accidents during transport, toxicity of plutonium, vulnerability of the

\begin{tabular}{|c|c|}
\hline & A Nuclear Glossary \\
\hline${ }^{233} \mathrm{U}$ & $\begin{array}{l}\text { - A fissile isotope of uranium } \\
\text { produced from }{ }^{232} \mathrm{Th}\end{array}$ \\
\hline${ }^{235} \mathbf{U}$ & $\begin{array}{l}\text { - A naturally occurring fissile isotope } \\
\text { of uranium }\end{array}$ \\
\hline${ }^{238} \mathbf{U}$ & $\begin{array}{l}\text { - The abundant naturally occurring } \\
\text { isotope of uranium }\end{array}$ \\
\hline${ }^{232} \mathrm{Th}$ & - Naturally occurring thorium \\
\hline${ }^{239} \mathrm{Pu}$ & $\begin{array}{l}\text { - Artificially produced plutonium; } \\
\text { this isotope can be used as a } \\
\text { nuclear fuel just as can }{ }^{233} \mathrm{U} \text { and } \\
{ }^{235} \mathrm{U} \text {. }\end{array}$ \\
\hline${ }^{240} \mathbf{P u}$ & $\begin{array}{l}\text { - An artificially produced isotope of } \\
\text { plutonium }\end{array}$ \\
\hline Breeder & $\begin{array}{l}\text { - A reactor that produces more } \\
\text { nuclear fuel than it burns }\end{array}$ \\
\hline Burner & $\begin{array}{l}\text { A reactor that burns more nuclear } \\
\text { fuel than it produces }\end{array}$ \\
\hline EBR-II & $\begin{array}{l}\text { - A } 60 \text {-megawatt experimental } \\
\text { breeder reactor }\end{array}$ \\
\hline$M W(e)$ & $\begin{array}{l}\text { - The unit of electrical power of a } \\
\text { nuclear reactor as opposed to } \\
\text { thermal power }\end{array}$ \\
\hline $\begin{array}{l}\text { GWe } \\
\text { Quad }\end{array}$ & $\begin{array}{l}\text { - A billion watts of electric power } \\
-1 \text { quadrillion British thermal units }\end{array}$ \\
\hline
\end{tabular}




\section{An Acceptable Nuclear Future}

nuclear system to sabotage and diversion. Most of my proposals will be aimed at remedying the present system's deficiencies in this general area.

The first concern, growth, we cannot remove by devising an acceptable nuclear future. Indeed, if one is convinced that growth is intrinsically bad, then one has relatively little incentive to devise such a future, since any nuclear future makes growth, or at least a shift to electricity, more feasible. If this belief comes to dominate, and we adopt an extremely low-energy, nonelectric style of living, then it is doubtful that nuclear energy can survive in any case. But the remaining two concerns-proliferation and safety in the broad sense -I believe can be ameliorated without rejecting nuclear energy.

The nuclear energy system comprises mining, enrichment, fuel fabrication, reactor construction and operation, reprocessing, and waste disposal. It is complex and intricate. The larger the system, the greater are the chances for system breakdown, since there are more points that are vulnerable. All of the concerns increase as the amount of nuclear energy increases. If the nuclear enterprise were small, and served merely as a short-term transition to other, more benign forms of energy, the concerns would be small and limited. The issues become stark and urgent only when the nuclear system becomes very large, and is regarded as the energy mode that will continue far in the future.

Thus if we are to design an acceptable nuclear system, we must first agree on criteria for acceptability, not merely when the system is small but when the system is large, and the full systems problems emerge. In theory we must decide, for example, what calculated reactor accident probabilities, or how much flow of plutonium, or how big an inventory of wastes in a fully deployed system are acceptable. We cannot, of course, state precisely the acceptable thresholds for these probabilities. We can, however, estimate these probabilities and their implications in a fully deployed system, and then see what can be done to reduce these probabilities.

\section{THE TWO PHASES OF NUCLEAR ENERGY}

Nuclear energy will develop in two phases, Phase I and Phase II. Phase I is based on reactors that burn ${ }^{235} \mathrm{U}$, Phase II on breeders that essentially burn ${ }^{238} \mathrm{U}$ or ${ }^{232} \mathrm{Th}$. We cannot say with assurance when Phase II will displace Phase I, since we do not know how much uranium we have. This is the strategic dilemma that has always plagued development of nuclear energy. Some of the early workers, notably Walter Zinn and Eugene Wigner, hoped to avoid this dilemma by skipping Phase I altogether. It was on this account that most of the original civilian reactor development at both Argonne National Laboratory and Oak Ridge National Laboratory was centered on the breeder. Others, notably Bennett Lewis of Canada, disagreed: Nuclear energy based on ${ }^{2:-U} \mathrm{U}$, possibly enhanced with the introduction of advanced converters, was a sufficient goal. "Breeders are not necessary," thundered Bennett Lewis in the 1950s; and even Eugene Wigner, who considered the enterprise valid only if the breeder were developed, conceded that the breeder might develop out of the technology of burners, rather than developing entirely de nouveau.

Phase I is self-limiting. We can estimate its magnitude if we can estimate the reserve of uranium cheap enough to be used in a burner. We may take for this the official figure of 3.5 million tons in the United States, though we recognize that the acceptable cost, both economic and environmental, of uranium usable in a burner may increase if we are badly strapped for a nonfossil energy source. The uranium required to inventory and fuel a 1000-megawatt Light Water Reactor (LWR) for 30 years without recycle is about 6,000 tons, with full recycle about 4,000 tons. Thus our assumed uranium reserve will support between 600 and 900 large LWRs for their lifetime. The Institute for Energy Analysis's most recent "low" estimate of nuclear electricity in the year 2000 corresponds to about 300 LWRs, growing to, say, 400 LWRs by 2010 . Phase I then might run its course, say, 50 years later -by 2060.

Phase II, based on breeders, could last immeasurably longer, since the reserve of low-grade ${ }^{235} \mathrm{U}$ or 2:32-Th usable in the breeder is so great. Let us consider, somewhat arbitrarily, an ultimate Phase II comprising 1000 large breeders each operating at about 2000 MW (e). This system corresponds to 120 quads (q) being produced by nuclear energy. An alternative ultimate system might be half as large- 500 breeders corresponding to $60 \mathrm{q}$. Let us now estimate the risks implied in systems of this magnitude.

We do not have figures for probability of meltdown for Liquid Metal Fast Breeder Reactors (LMFBRs) assuming these are what we deploy-comparable to the estimates for LWRs. The latter probability as estimated in the well-known Rasmussen study is .00005 per 
reactor per year, of which only one-fourth grossly breach aboveground containment. If the LMFBR accident probabilities are the same as those estimated for LWRs, then the expected accident rate for the large system is .05 per year; for the small system, .025 per year-i.e., we can expect one accident every 20 or 40 years, depending on the size of the system.

Before asking whether this is good enough, we must recognize that by the time the ultimate United States system has been reached, the rest of the world will have also deployed many breeders. Scenarios have been developed at the Institute for Energy Analysis and the International Institute for Applied Systems Analysis that contemplate 10,000 large breeders. If the Rasmussen probabilities given above are taken seriously, then one estimates an accident, on the average, every two years.

This calculation illustrates the dilemma. From the point of view of an operator or utility operating a single reactor, 1 chance in 20,000 per year is acceptable. On the other hand, from the point of view of the system as a whole, it would seem the probabilities ( 1 every 2 years) are too high. Just as all DC-10s are grounded if too many DC-10s anywhere in the world misbehave, so one would imagine that breeders simply would not survive if, on the average, one of them melted every two years - and this is independent of whether the meltdowns occurred in the U.S. or elsewhere.

The same problems of system vulnerability, as opposed to individual vulnerability, apply to the other, less quantifiable risks. The U.S. system would contain some 2,500 to 5,000 tons of plutonium ( $\mathrm{Pu}$ ); the world system possibly 10 times as much. Whatever the risk of diversion or of contamination when the world inventory is, say 100 tons of Pu, these risks are certainly much larger when the inventory is 250 to 500 times larger. Or consider the matter of retired reactors. In a world of 10,000 reactors, some 300 would be retired every year, 300 new ones completed to replace them. Is this really credible?

When one looks at the matter from this point of view, one has almost reduced the full-scale deployment, worldwide, of breeders to an absurdity. Yet we cannot say any of this with certainty. Surely the gradual evolution of the technology will reduce the a priori risk probabilities. The legislated meltdown probability for LMFBRs of .000001 per reactor year, if achieved, would relieve much of our concern about large accidents. Some 40 years ago a distinguished Swedish aero- nautical engineer estimated that if as many airlines fiew as fly today, we could expect a crash every two days!

The system will inevitably be self-limiting: It will expand only to a size with which the socicty is comfortable, and this size will depend primarily upon the state of the technology. But no matter the state of the technology, we shall have to exercise non-technical ingenuity to reduce the risks, even though they cannot be quantified. In particular, what we seek are mechanisms that will:
Minimize the likelihood of physical disaster
Minimize the consequences of disaster
Ensure institutional responsibility for as long as the nuclear system requires care

I would suggest the following measures will be required if Phase II - which may be very large and last for a very long time-is to be acceptable.

Physical isolation. It seems evident that only a relatively small fraction of our planet ought ever to be in contact with high-level radioactivity-and the smaller the better. This leads to the idea of committed sites surrounded by sparsely populated areas-in short, to a strongly collocated system. One thousand reactors might be accommodated in 5,000 square miles within the United States-say, 100 sites each containing 10 reactors and supporting chemical facilities occupying 40 square miles apiece, and 1,000 square miles for waste disposal. Some of these sites would be in the oceans; many of them would represent expansions of current nuclear plant sites.

The appropriate degree of collocation is negotiable. If breeders and their chemical plants are collocated (a return to the original concept of the breeder as a closely coupled reactor and a chemical plant), one minimizes transport of plutonium; on the other hand, the optimal size of the chemical plant may not match the output of the cluster of reactors, and in any case, as Phase II gets under way, transport of fuel between the reactors and off-site chemical plants is inevitable.

A firm national commitment to the principle that the nuclear enterprise is to be confined to as few sites as possible seems to me the very minimum. A more farreaching policy - that all breeders and their supporting facilities shall be collocated-seems to be indicated, though this stronger policy is more open to argument.

continued on page 26 


\section{An Acceptable Nuclear Future ... continued from page 7}

Strengthened security. In a world beset by terrorism, we are confronted with unsatisfactory alternativesterrorism with few constraints on individual rights, or order with considerable restraints. Yet I believe we can have order without losing freedom on a large scale. We can cope with terrorism, sabotage, and diversion by strengthening security at vulnerable spots, without having to impose repressive measures upon the entire society. Thus, physically isolated nuclear sites lend themselves to being made secure by virtue of their isolation. But this may not be enough. We will probably have to reimpose on our nuclear plants the same kind of security we imposed on them during the war. In effect, we will have to buy order at the expense of freedom, as has been the case throughout man's history, but we confine these encroachments on freedom to 5,000 square miles and perhaps 200,000 people-the cadre that operates the nuclear plants.

Professionalization of the nuclear cadre. In the final analysis, the safety and integrity of the nuclear system will depend on the caliber of the staff that mans the system. If one concedes that the nuclear system is special, because a malfunction could cause very great harm, and of a kind that our society has not become accustomed to (and may never become fully comfortable with), then it follows that a higher degree of professionalism and dedication is required to manage and operate the nuclear system than is required for the conventional power system. The responsibility borne by the superintendent of a nuclear power plant is at least as great as that borne by the pilot of a 747 . This must be recognized-by the superintendent, by his management, and by the public.

1 believe this sense of professionalism is enhanced by the siting scheme that $\mathrm{I}$ propose. I draw this inference from our experience at the existing large nuclear sites-Hanford, Oak Ridge,
Idaho Falls, Savannah River. Each of these places, somewhat isolated, somewhat self-contained, tends to create a cadre, a sense of professionalism and of commitment, that is possibly less easy to create in smaller sites that give less scope for a cadre of critical size to develop.

Establishment of nuclear generation consortia. When nuclear reactors were first introduced, they were viewed simply as replacements for conventional boilers. This was a mistake. The nuclear system is a far more complex and demanding enterprise than is a coal-fired boiler. The responsibility inherent in and the complexity of a nuclear system, particularly a breeder. go much beyond that involved in a fossil-fuel system.

The breeder system, with its intrinsically closer coupling between chemical reprocessing and reactor operation, places demands on the utility industry that go even further beyond that industry's tradition. Indeed, the split between chemical reprocessing and reactor operation inherent in the ceramic-fueled LMFBR was to a degree encouraged by the utility industries' disinclination to go into the chemical reprocessing business. But it is by no means clear that ceramic-fueled LMFBRs will always dominate the nuclear enterprise. As the technology is rationalized, other breeder systems in which chemical reprocessing and reactor operation are more closely coupled could well come into being.

It would seem therefore that in the ultimate system the generation of nuclear electricity, as contrasted with its distribution, ought to be placed in the hands of utilities that are specifically geared for this job. A siting policy such as we have enunciated would lend itself to just such separation. Generation would be the responsibility of the company or consortium or government entity established specifically to carry out this task. Consortia of this sort already operate the nuclear power plants in New England, and governmental generating entities such as the Power Authority of the State of New York or the Tennessee Valley Authority are also examples.

The nine existing Reliability Councils in the U.S. conceivably could serve as nuclei for the creation of such generating consortia. However, our purpose here is not to restructure the electrical utility industry in order to rationalize the distribution of electricity; it is to create entities equal to the responsibility imposed by the generation of nuclear energy.

Not the least of these responsibilities is the handling of a serious accident, even one that does little or no harm to the public. One can never simply abandon a nuclear plant, least of all one that has suffered a meltdown. Yet what assurance do we have now that the utilities operating reactors are robust enough to withstand the stress imposed by an accident; and if a utility goes bankrupt, is the nuclear plant assured the resources needed to keep it from causing damage? Thus, along with the restructuring I speak of, I would contemplate some means of preventing responsibility from lapsing, in the event an accident causes bankruptcy.

Longevity of institutions responsible for nuclear energy. The nuclear system, once started, can hardly be abandoned. Who, for example, is responsible for cleaning up once a nuclear fuel chemical plant has gone out of business? This residual responsibility is not unique to nuclear energy. Abandoned strip mines continue to cause acid drainage, and no one can be held responsible. The difference perhaps is that we know in advance that a nuclear plant cannot simply be abandoned; the same knowledge was not so apparent in the case of acid mine drainage.

We have already recognized that waste disposal, which involves some surveillance over a long time, must be 
a governmental responsibility - as much as anything because of all our institutions, it is the government which is longest-lived. Probably other elements of the nuclear system will also demand such longevity and possibly stronger governmental involvement. At the very least, in the ultimate system we must be assured that whatever entity is responsible for the operation of the reactors is likely to remain viable as long as the reactors contain appreciable amounts of radioactivity.

THE ACCEPTABILITY OF PHASE I AND THE TRANSITION TO PHASE II

The requirements we lay down for an acceptable Phase II are stringent: physical isolation and collocation, strengthened security, professionalization of the cadre, establishment of generating consortia, and longevity of the operating entities. These requirements seem to me necessary if the ultimate nuclear energy system is as large as 500 or 1,000 breeders in the United States, and ten times that many in the world; and if the system is to be with us for an indefinitely long time.

How much of this is required to make Phase I acceptable? I would argue, not very much; because Phase I is limited in size and duration. Again, assuming the 3.5 million tons for the raw material in the United States, we compute one expected meltdown in all of Phase I. And it is reasonable to expect that the incremental improvements in the technology of safety will reduce this expected number. The likelihood is that Phase I will pass without any serious meltdown. The same argu-ment holds with respect to the other issues. Because Phase I is limited, incremental improvements in security, in professionalization of the cadre, and in ensuring financial responsibility ought to be sufficient.

On the other hand, it seems to me that Phase I ought to develop along paths that smooth the transition to an acceptable Phase II. Of major import is the siting policy. Ought we not estab- lish the sites for nuclear energy now, and adopt the principle that only sites so committed, most of which will be occupied first by LWRs, will be used for the breeders; and that we shall keep the number of such sites to a minimum? We may achieve this policy de facto simply because it is becoming so hard to license new sites. C. Burwell estimates that 80 of the 100 existing sites could be expanded into large centers.

Would it not be prudent to confine the future nuclear system, including the rest of Phase I, essentially to the existing sites, and to adopt this as our national policy? Reprocessing and fabrication facilities should be collocated -all seem to agree on this. I would go further and urge that chemical complexes be collocated with existing nuclear sites. Though I believe eventually all such reprocessing complexes ought to be collocated with breeders, I am prepared to leave this question open for the time being. Simply do not put new complexes anywhere except in places where nuclear energy centers already exist or are planned.

The key question with respect to Phase II is the rate at which it develops, and the speed with which breeders are introduced. The original plan for introduction of the breeder as outlined in the 1962 White Paper of the Atomic Energy Commission (AEC) was predicated upon a much faster growth of electricity than we now consider plausible -an electrical demand of $70 \mathrm{q}$ by 2000 and doubling every 15 to 25 years thereafter. No wonder the U.S. drive toward fast deployment of the breeder seemed so obviously sound.

But more recent estimates of our demand for electricity are much more modest - for example, at the Institute for Energy Analysis we now project demand for nuclear electricity of 300 to $400 \mathrm{GWe}$ ( 18 to $24 \mathrm{q}$ ) by 2000 . And A. M. Perry and M. J. Ohanian at IEA have estimated that a total nuclear demand of 400 GWe could be achieved by 2000 even if the first commercial
LMFBR were not deployed until the year 2000 , and the total uranium resources were only 1.8 million tons. This relatively leisurely introduction of breeders would limit our total nuclear capacity of 400 GWe until around 2020. By then the system could resume growth as old breeders fed fissile material into new ones. In the intervening years one would presumably depend on additional lower grade ore, should demand exceed 400 GWe.

Although most of us in the nuclear enterprise have always believed that the breeder is the essence of nuclear energy, we could never mount a completely compelling argument for introducing it very quickly, except the one based on an extremely rapid and most unlikely rise in energy demand, or a very much smaller uranium ore reserve than we now consider likely. In the absence of such a strong demand or lower reserve our argument for quick deployment fell back on economicswe believed breeders would be cheaper than burners, in which case the market would force rapid deployment of breeders.

Eventually this will be the case; but it is not at all clear when, since neither the future price of uranium nor the capital cost of the breeder is known. To be sure, if breeders instead of burners were now deployed, most of the questions concerning separative work capacity and uranium ore would disappear - the nuclear system would have fewer links, and therefore would be less subject to total failure as a result of failure of a single link.

Though this cannot be looked upon as a completely compelling argument for rapid deployment of the breeder, it reinforces this fundamental fact: Nuclear energy based on breeders is much less beset by uncertainties related to our energy demand, our ore reserve, or our separative work capacity than is nuclear energy based on burners. This, in final analysis, is the strongest argument for fast rather than slow deployment of breeders. 


\section{An Acceptable Nuclear Future ... continued}

PROLIFERATION - THE BOGEYMAN

President Carter's new look at nuclear energy, particularly his deferral of recycling in LWRs and his deferral of LMFBRs, has been largely motivated by his concerns over proliferation. It is curious that technologists tend to look upon proliferation as a political problem amenable only to political solutions, whereas politicians regard the problem as amenable to technological fixes. Hence the President's call for development of proliferation-resistant reactors. History has come full circle; 31 years ago Dean Acheson and David Lilienthal proposed a plan for control of nuclear energy that depended heavily on a technological fix, the division of nuclear activities into dangerous and nondangerous ones. The technological key to this distinction was the possibility of extracting power from denatured fissile materials, i.e., isotopic mixtures of ${ }^{233} \mathrm{U}$, ${ }^{235} \mathrm{U}$, and ${ }^{23} \mathrm{U}$, or (as was then somewhat mistakenly believed) ${ }^{239} \mathrm{Pu}$

${ }^{210} \mathrm{Pu}$. Thus nuclear activities could be separated into dangerous and nondangerous ones, the former being supervised by an international authority, the latter being conducted under national auspices. Though a special committee set up by General Groves warned that denaturing could not be foolproof, the Acheson-Lilienthal plan nevertheless relied on such approaches.

Today we again seem to be casting about for a technological solution to proliferation based on denaturing. Now it is certainly true that the world community of reactor developers has never considered building in resistance to proliferation as a design constraint. I suspect that schemes such as Molten Salt Breeder Reactors (MSBRs) fueled with ${ }^{233} \mathrm{U} /{ }^{238} \mathrm{U}$ mixtures are more proliferation-resistant than are reactors that use pure ${ }^{2 * 9} \mathrm{Pu}$; and I believe it is useful for the reactor community to examine reactor systems that incorporate technical barriers to proliferation, or at least weaken the link between power and bombs.
But it is clear that institutional arrangements must be part of any proliferation-resistant system, and this certainly was anticipated in the Acheson-Lilienthal ideas for an International Atomic Energy Authority. I would argue that the policy of collocated nuclear energy centers espoused here could itself strengthen resistance to proliferation even without a fullfledged international authority. The point is that such a siting policy, which confines nuclear energy to relatively few large sites with a minimum of transport of fissile material, is in the first place easier to inspect by the instruments of the present International Atomic Energy Agency; and it lends itself to resident inspectors who could insinuate themselves into the local situations and detect unauthorized activities much more readily than could non-resident inspectors. Indeed, I should think that once the principle of resident inspection is adopted, the IAEA would have taken an important step toward becoming the sort of international entity conceived in the Acheson-Lilienthal plan.

Let me put the pieces of what I think is an acceptable nuclear future together. My basic point is that if we can devise an acceptable long-range system-that is, Phase II-then much of the opposition to the much smaller and limited Phase I ought to gradually subside, without either a dismantling of Phase I or a rejection of Phase II. The basic elements of Phase II are physical isolation (and therefore collocated energy centers and resident IAEA inspection); heavier security; professionalization of the cadre; longevity of the operating entities; and restructuring of the nuclear energy system, with the establishment of consortia for the generation of nuclear power. In preparation for the transition to Phase II, I would urge that any new reactors, whether breeders or LWRs, be confined essentially to existing sites. I also urge further strengthening of the nuclear cadre during Phase I, and re- examination of reactor systems with a view to hardening them against proliferation.

It must be noted that these proposals are aimed more at improving the safety, rather than the proliferationresistance, of the nuclear system. Nevertheless collocation should enhance the proliferation-resistance as well as the safety of the nuclear system. Resident inspection is more feasible if collocated energy center sites are adopted. A nation bent on milking its nuclear power plants of weapons materials would almost surely have first to expel its resident inspectors. This would be tantamount to publicly and explicitly going nuclear, in much the same sense that Egypt's expulsion of UN observers from the Sinai signaled its intention to go to war. Moreover, a collocated system-for example, a closely coupled breeder and chemical plant (like EBR-II or the Molten Salt Reactor)-would inherently be more proliferation-resistant and diversion-proof than would a dispersed system since the fuel need never be fully decontaminated.

Is it likely that suggestions such as these will quiet the concerns over nuclear energy enough to establish a "consensual climate" in which the regulatory process can work during Phase I? At the moment I would judge that these proposals do not go far enough for the antis, and go too far for the pros. The situation is ripe for imaginative, constructive thinking. I look on these proposals as tentative first stepsindeed, as an invitation for those who are interested to suggest means of remedying the ills of the nuclear business. Consensual climates in a democracy are not easy to forge, especially when the issues are bitter and important. Yet, unless we establish such a climate, we run a danger of losing the nuclear option. I believe the burden we would thereby impose on our descendants is much heavier than the one they would have to bear in managing an acceptable nuclear future. 